\title{
Prevalence of Thyroid Disease among the Diabetic Patients: A Meta Analysis
}

\author{
Authors \\ Ankita Sharma ${ }^{1}$, V.K Shivgotra ${ }^{2}$ \\ Department of Statistics, University of Jammu, Jammu \\ Jammu and Kashmir \\ Email:ankitareasi@gmail.com
}

\begin{abstract}
India, being the developing country is facing lot of problems related to thyroid and diabetes. With the widespread availability of thyroid function testing in recent years, numbers of patients with symptoms, which might be attributable to hypothyroidism and hyperthyroidism, are being tested. The present study aims at finding the prevalence of thyroid disease among the diabetic patients in India. We have incorporated 14 studies from different parts of the country being conducted for testing thyroid problems in diabetic patients and found out that $24.2 \%$ (95\% CI 20.73 -27.78) persons of total population were having the thyroid diseases.
\end{abstract}

Keywords- Prevalence, Thyroid, Diabetes, Hypothyroidism, Hyperthyroidism, Confidence Interval.

\section{Introduction}

Diseases of thyroid gland are among the most common endocrine disorder affecting the population throughout the world. Thyroid diseases are very common these days and have brought focus on this by a wide range of surgeons and doctors. With the widespread availability of thyroid function testing in recent years, increasing numbers of patients with symptoms, which might be attributable to hypothyroidism and hyperthyroidism, are being tested. It was been estimated that about 42 million people in India have thyroid dysfunction ${ }^{[1]}$. Thyroid show variation with age, sex, dietary habits, stress and geographical location. Diseases of the thyroid gland are among the most abundant disorders worldwide second only to diabetes. The most common thyroid problems involve abnormal production of thyroid hormones. Too much thyroid hormone results in a condition known as hyperthyroidism and hypothyroidism conversely. Diabetes Mellitus (DM) and thyroid dysfunction (T D) are the most common endocrine di-sorder. The association between DM and TD is widely known, with the first studies published in $1972^{[2]}$. Thyroid disorder can have a major impact on glucose control, and untreated thyroid disorder can affect how the diabetes is managed. Hypothyroidism can decrease the insulin requirement in patients with diabetes, and hyperthyroidism may worsen glucose tolerance or control. In general population, approximately $6 \%$ of people have some form of thyroid disorder. However, the prevalence of thyroid disorder increases to over $10 \%$ in people with diabetes. Since people with one form of autoimmune disorder have an increased chance of developing other 
autoimmune disorders, people with Type 1 diabetes have a higher risk of autoimmune thyroid disorder. Up to $30 \%$ of women with Type 1 diabetes have some form of autoimmune thyroid disease. Postpartum thyroiditis, a form of autoimmune thyroid disease that causes thyroid dysfunction within a few months after delivery of a child, is three times more common in women with diabetes. Although Type 2 diabetes is not an autoimmune disorder, there have been many reports showing a higher occurrence of thyroid diseases, particularly hypothyroidism, among people with Type 2 diabetes. There are several studies were conducted in different countries to estimate the prevalence of thyroid in diabetic patients. There is great variability in the prevalence of thyroid dysfunction in general population, ranging from $6.6 \%$ to $13.4 \% .{ }^{[3][4]}$ But in diabetics patients, the prevalence is still greater and varies from 10 to $24 \%{ }^{[4][5]}$. These differences can be explained by different diagnostic criteria of thyroid dysfunction, degree of iodine intake in different people and different sensitivities of TSH and the large population diversity ${ }^{[6]}$. Thyroid diseases is a pathological state that adversely affect diabetics control and is commonly found in form of $\mathrm{DM}$ (diabetes mellitus) which is associated with advanced age in Type 2 diabetes and autoimmune diseases in Type 1 diabetes.DM appears to influence thyroid function in two sites ;firstly at the level of hypothalamic control of TSH release and secondly at the conversion of $T_{4}$ to $T_{3}$ in the peripheral tissue. The WHO estimate of diabetes prevalence for all age group worldwide was $2.8 \%$ in 2000 to 366 million in $2030^{[7]}$. Since, a number of studies have estimated the prevalence of thyroid dysfunction among patients to varying from 2.2 to $17 \%^{[8]}$. However, some studies have estimated much higher prevalence of thyroid dysfunction in diabetes $31 \%$ to $46.5 \%^{[9][2]}$. A study was carried out among diabetic patients in Calabar, Nigeria for which 161 diabetic subjects and 105 non-diabetic controls were selected. The authors reported a high incidence (46.5\%) of abnormal thyroid hormone levels among diabetic patients.

\section{Method and Material}

Meta-analysis is broadly defined as the quantitative review and synthesis of the results of related but independent studies. These studies usually originate from the published literature. Meta-analysis, when well designed and appropriately performed, is a powerful tool for synthesis. It is an analytical method where both independent and different studies are integrated and their results pooled into a single common result. The meta-analysis, when compared to other forms of reviewing separate studies, has the great advantage of being less influenced by the personal opinion of the reviewer, and provides unbiased conclusions Meta-analysis become an increasingly important technique in medical research.

We searched MEDLINE/Pub Med, Google scholar, EMBASE, and reference lists of prevalence studies from January 2008 to August 2015, We used combinations of medical subject headings (MESH) and free text words that included search terms related to the exposure (e.g., thyroid, DM, hyperthyroidism, hyperthyroidism), which were combined with search terms related to the outcomes (e.g., prevalence, disease burden, estimate). We identified articles eligible for further review by performing an initial screen of identified titles or abstracts, followed by a full-text review. Internet searches used permutations of medical subject headings for prevalence studies on Thyroid in India. The characteristics of included studies for the Metaanalysis are summarized in Table where we have provided all relevant the details namely author name, year of publication, age, state of the study, zone total number of subjects, number of cases and gender respectively. We have checked the eligibility of all the studies for our analysis i.e whether they are relevant or not to our study. Forest plot was used to show the extent of heterogeneity among studies .Since the heterogeneity was measure the degree of inconsistency among the studies. Cochran $\mathrm{Q}$ and $I^{2}$ is used to measure the heterogeneity and inconsistency across the studies. The meta-analysis was performed using Metaxl Software (version 2.2). It is important to be familiar with the type of data 


\section{JMSCR Vol||05||Issue||06||Page 23385-23389||June}

(e.g. dichotomous, continuous) that result from measurement of an outcome in an individual study, and to choose suitable effect measures for comparing intervention groups.

\section{Results}

Though out the world all studies had established thyroid prevalence more among women suffering from diabetes. So, we have considered various studies with reference to prevalence of thyroid among diabetic population.

The characteristics of included studies for the Metaanalysis of diabetes patients with thyroid disease were summarized in a Table. After analysis of 1640 diabetic subjects from fourteen studies, the prevalence of thyroid among the diabetic population was found to be $24.17 \%$ (95\% Cl:20.73\%-27.18\%). However, calculation of the heterogeneity statistic $\left(\mathrm{I}^{2}=63.66 \%\right.$ and Cochran's $\left.\mathrm{Q}=35.776, \mathrm{p}<0.0001\right)$ indicated significant heterogeneity prevalence of thyroid between the studies. However, the highest prevalence of diabetes in the earlier studies was reported by Demitrost ${ }^{[10]}$ and Makandar ${ }^{[11]}$. The prevalence of thyroid reported by Demistrost ${ }^{[10]}$ was $31.19 \%$ in the early study conducted on Imphal from January 2011 to July (2012) and in this study 61 males and 141 females were included. Out of the 61males, 16 have thyroid disease and among

141 females, 47 have thyroid disease. Most commonest age group affected by thyroid disorder was 45-65 years. Makandar ${ }^{[11]}$ reported $32 \%$ among the total patients had abnormal thyroid hormone, $22 \%$ of them had hypothyroidism and $10 \%$ had hyperthyroidism. Figure 4.5 shows all the detailed analysis graphically.

The prevalence of thyroid reported by Singh $\mathrm{G}^{[12]}$ was $23.75 \%$ in the early study conducted on Civil Hospital, Jalandhar and Amirtsar. In this study, there were 80 subjects of diabetes. Out of the 80 diabetic subjects studied, 36 were males and 44 were females. Total prevalence of the thyroid disease in 80 diabetic patients was (23.75\%), $22 \%$ males and $25 \%$ females had thyroid. Such result showed that thyroid disorders were most common in females than males which are similar to our study in the present work. The difference in prevalence is due to number of studies included, age-group, zone difference, region difference and nature of the population included in the study.

\section{Forest Plot}

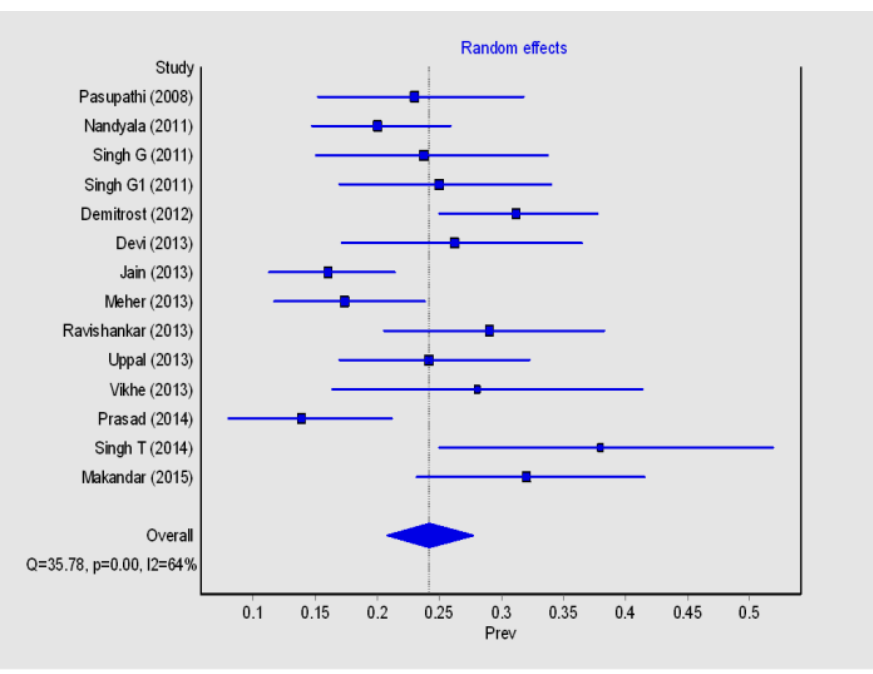

Fig 1. Prevalence of Thyroid

Table 1 -Test of Heterogeneity

\begin{tabular}{|l|c|c|c|c|}
\hline $\begin{array}{l}\text { Test of } \\
\text { Heterogeneity }\end{array}$ & Prevalence & LCL95\% & HCL95\% & Weight(\%) \\
\hline $\begin{array}{l}\text { Pooled } \\
\text { Statistics }\end{array}$ & 24.17 & 20.73 & 27.78 & 100 \\
\hline I-squared & 63.66 & 35.51 & 79.52 & \\
\hline Cochran's Q & 35.78 & & & \\
\hline Chi2, p & 0.001 & & & \\
\hline tau2 & 0.015 & & & \\
\hline
\end{tabular}

Table 2- Thyroid Prevalence

\begin{tabular}{|l|c|c|c|c|c|c|}
\hline Study & Total & Cases & Prevalence & $\begin{array}{c}\text { LCL } \\
\mathbf{9 5 \%}\end{array}$ & HCL95\% & $\begin{array}{c}\text { Weight } \\
(\%)\end{array}$ \\
\hline Pasupathi $^{[13]}$ & 100 & 23 & 23 & 15.23 & 31.8 & 7.02 \\
\hline Nandyala $^{[14]}$ & 200 & 40 & 20 & 14.73 & 25.85 & 8.75 \\
\hline Singh G $^{[12]}$ & 80 & 19 & 23.75 & 15 & 33.75 & 6.39 \\
\hline Singh G1 $^{[15]}$ & 100 & 25 & 25 & 16.96 & 34 & 7.02 \\
\hline Demitrost $^{[10]}$ & 202 & 63 & 31.19 & 24.97 & 37.76 & 8.77 \\
\hline Devi $^{[16]}$ & 80 & 21 & 26.25 & 17.13 & 36.5 & 6.39 \\
\hline Jain $^{[1]}$ & 200 & 32 & 16 & 11.22 & 21.43 & 8.75 \\
\hline Meher $^{[17]}$ & 150 & 26 & 17.33 & 11.66 & 23.84 & 8.08 \\
\hline Ravishankar $^{[18]}$ & 100 & 29 & 29 & 20.48 & 38.32 & 7.02 \\
\hline Uppal $^{[19]}$ & 120 & 29 & 24.17 & 16.89 & 32.27 & 7.51 \\
\hline Vikhe $^{[20]}$ & 50 & 14 & 28 & 16.32 & 41.36 & 5.04 \\
\hline Prasad $^{[21]}$ & 108 & 15 & 13.89 & 7.94 & 21.12 & 7.23 \\
\hline Singh T $^{[22]}$ & 50 & 19 & 38 & 24.96 & 51.95 & 5.04 \\
\hline Makandar $^{[12]}$ & 100 & 32 & 32 & 23.18 & 41.51 & 7.02 \\
\hline
\end{tabular}




\section{Conclusion}

The present analysis of diabetic patients which were not representing the whole population reported that the prevalence of thyroid diseases among the diabetic patients is estimated is $(24.2 \%)$ which is lower than the prevalence reported by Singh $\mathrm{T}^{[21]}$ in a recent cross-sectional study conducted among diabetic population of Punjab. However Makandar $^{[12]}$ reported (32\%) in Delhi and showed diabetic with thyroid disease had poor glycemic control. The lowest Prevalence of thyroid diseases in diabetic population reported by Jain ${ }^{[1]}$ in Punjab also showed significantly higher serum level of cholesterol and triglycerides. Severe diabetic complications where noted in patients with thyroid disorder.

\section{References}

1. Jain G, MarwahaT S, Khurana A and Dhoat P.S. Prevalence of Thyroid disorders in Patients of type 2 Diabetes Mellitus. International Journal of Medical and Dental Sciences.2013;2(2):153-161

2. Udiong, C.E.J., Udoh A.E. and Etukudoh M.E. Evaluation of thyroid function in diabetes mellitus in Calabar, Nigeria. Ind $\mathbf{J}$ Clin Biochem.2007;22(2): 74-78.

3. Singer $\mathrm{C}$ and Underwood E.A. A Short History of Medicine 2nd ed. Oxford University Press,Oxford. 1962;519-34.

4. Umpierrez GE, Latif KA, Murphy MB, Lam bert HC, Stentz F and Bush A. Thyroid dysfunction in patients with type 1 diabetes.Diabetes Care.2003;26: 1181-1115

5. Gharib H,Tuttle R.M, Baskim J, Fish L.H, Si nger P.A and Mc Dermott M. T. Consensus statement. Subclinical thyroid dy sfunction: a joint statement onmanagement $\mathrm{f}$ rom the American Association of Clinical E ndocrinologists, the American Thyroid Asso ciation and the Endocrine Society.J Clin End ocrinol Metab.2005;90:581-585

6. Chen.G, Juan .W and Yinghua.L. Associations between cardiovascularrisk, insulin resis tance, $\beta$ - cell function and thyroid dysfunctio $\mathrm{n}$ : a crosssections study in She ethnic min ority group of Fujian Province in China. Euro J Endocrinol.2010;163:775-782.

7. Faghilimnai, S, Hashemipour $\mathrm{M}$ and Kelishadi B. Lipid profile of children with type 1 diabetes compared to controls". ARYA .J.2006;2(1):36 -38.

8. Sailakshmi.M.P.A, Pavana G. A, Rekha B.R and Suhasini S.A. Autoimmune thyroid disease in pregnancy". Int $\mathrm{J}$ Reprod Contracept Obstet Gynecol.2014;3:321-324

9. Celani M.F, Bonati M.E and Stucci.N. Prevalence of abnormal thyrotropin concentrations measured by a sensitive assay in patients with Type 2 diabetes mellitus. Diabete Res,1994;27(1):15-25.

10. Demitrost L and Ranabir S. Thyroid dysfunction in type 2 diabetes mellitus: A retrospective study. Indian Journal of Endocrinology and metabolism. 2012;16(2):1-5

11. Makandar A, Sonagra A and Shafi N. Study of thyroid function in type 2 diabetic and non-diabetic population. International Journal of Medical Science and Public Health,2015;4:769-772

12. Pasupathi P, Bakthavathsalam G, Saravanan $G$ and Ramachandran S. Screening for Thyroid Dysfunction in the Diabetic/NonDiabetic Population". Thyroid Science. 2008;3(8):01-05

13. Nandyala V, Gandiah P, Sivarajappa P and Indira G. Thyroid Disorders in Type 2 Diabetes Mellitus. International Journal of Recent Trends in Science And Technology.2013; 9:250-255.

14. Singh G,Gupta V,Gupta A and Gupta N. Frequency of Thyroid Dysfunction Among Diabetes in Punjabi Population. An International Journal.2011;3(1):74-77.

15. Singh G, Gupta V, Sharma A and Gupta N. Evaluation of Thyroid Dysfunction Among type 2 diabetic Punjabi Population. Advances in Bioresearch.2011;2:03-09 
16. Devi A, Singh S. and Singh L. Thyroid Hormone Dysfunctions in Type 2 Diabetic Patients in Urban Areas of Manipur. International Journal of Pharmaceutical Science Invention.2013;2:07-09.

17. Meher L.K, Suryanath R, Kota S.K, Sarangi J. and Jali S. Prevalence of hypothyroidism in patients with metabolic syndrome. Thyroid Resea rchand Practice. 2015; 10(2): 60-64.

18. Ravishankar,Champakamalini,Venkatesh and Mohsin. A prospective study of thyroid - dysfunction in patients with Type 2 diabetes in general population. .IMedPub Journals.2013;5

19. Uppal V,Vij C, Bedi G,Vij A and Banerjee B.Thyroid Disorders in Patients of Type 2 DiabetesMellitus.Indian J Clin Biochem. 2013;28(4):336-341.

20. Vikhe V, Kanitkar S,Tamakuwala K, Gaikwad1 A, Kalyan M and Agarwal R. Thyroid dysfunction in patients with type 2 diabetes mellitus at tertiary care centre. National Journal of Medical Research.2013;3:377-380.

21. Prasad D and Devasena I. The Thyroid Profile in Type 2 Diabetes Mellitus and its Significanc. International Journal of Scientific Research; 2014;3:01-03

22. Singh T and Kaur J. Evaluation of Thyriod Dysfuction in Patients suffering from Diabetes mellitus in a tertiary care Hospital. International Journal of Bioassays. 2014;3:3574-3576. 